

\title{
Antidiarrhoeal activity of ethanolic stem bark extract of Newbouldia laevis in castor oil-induced diarrhoea in rats

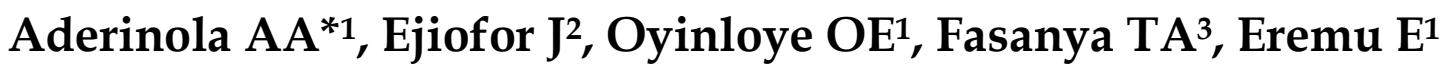 \\ 1Department of Pharmacology, Olabisi Onabanjo University, Sagamu, Ogun State, Nigeria ${ }^{2}$ Department of Pharmacology and Therapeutics, Ahmadu Bello University, Zaria, Nigeria ${ }^{3}$ Department of Biochemistry, Olabisi Onabanjo University, Sagamu, Ogun State, Nigeria
}

\author{
*Correspondence: AA Aderinola, Department of Pharmacology, Faculty of Basic Medical Sciences, \\ OlabisiOnabanjo University, PMB 2002, Ago-Iwoye, Nigeria. Email: aderonkeaderinola@yahoo.com; \\ ORCID - https://orcid.org/0000-0003-3683-1060
}

\begin{abstract}
Background: Diarrhoeal disease is the second leading cause of morbidity and mortality in developing countries requiring urgent attention. Many of the conventional anti-diarrhoeal drugs cause serious adverse effects, hence the need to screen various plants for their medicinal values becomes imperative.

Objective: To investigate the anti-diarrhoeal activity of ethanolic stem bark extract of Newbouldia laevis in castor-oil induced diarrhoea in rats.

Methods: The stem bark of Newbouldia laevis collected from Abeokuta, Ogun State, was air-dried, ground, macerated in $90 \%$ ethanol and concentrated to dryness in a water bath and then reconstituted using distilled water. Fifty (50) albino rats of both sexes used for the study were divided into two groups: A and B with twenty-five (25) rats per group.

Group A was used for the gastro-intestinal motility test using charcoal meal while

Group B was used for castor-oil induced diarrhoea test and the number of stool pellets was counted over an hour period.

Results: The extract $(250-1000 \mathrm{mg} / \mathrm{kg})$ showed significant $(\mathrm{p}=0.0399)$ anti-diarrhoeal activity by decreasing the distance of the gastrointestinal movement of charcoal meal in the treated rats and also inhibited the severity of diarrhoea induced by castor-oil in a dose-dependent manner when compared with the control (distilled water). This activity could be attributed to phytochemicals like flavonoids and tannins present in Newbouldia laevis.

Conclusion: The results showed that stem bark extract of Newbouldia laevis possesses a significant anti-diarrhoeal property and this supports the traditional use of the plant in the treatment of diarrhoea.
\end{abstract}

Keywords: Antidiarrhoeal activity, Castor oil, Charcoal meal, Gastro-intestinal motility, Newbouldia laevis.

\section{Introduction}

Diarrhoea refers to increased frequency of passage and decreased consistency of faecal matter as compared to an individual's normal bowel pattern. ${ }^{[1]}$ It involves both an increase in the motility of the gastrointestinal tract, along with increased secretion or decrease in the absorption of fluid with loss of electrolytes (particularly sodium) and water. ${ }^{[2]}$ According to 
the World Health Organization, diarrhoea is defined as the passage of three or more loose or watery stools per day or as passing more stools than normal for the individual. [3] It is one of the water-borne diseases endemic in many regions of the world and considered to be a major health threat to the world population both tropical and subtropical poor countries. ${ }^{[4]}$

Diarrhoeal diseases constitute a major cause of morbidity and mortality worldwide; especially in developing countries. It was the second most common cause of death in children younger than five years; more than five million children under the age of five years die every year due to diarrhoea. ${ }^{[5]}$ Reports have shown that cases of diarrhoea are estimated at 1.7 to 5 billion per year, $[6,7]$ and diarrhoea caused a total of 0.76 million $(11 \%)$ deaths in children aged less than five years old in 2012, [8] 1.26 million deaths in 2013, ${ }^{[9]}$ and 1,655,944 deaths with 446,000 deaths occurring among children aged less than five years in 2016. [10,11]

The most common cause of diarrhoea is an infection of the intestine by viruses, bacteria or parasites, [12] - a condition known as gastroenteritis. These infections are often acquired faeco-orally or directly from another person who is infected. Diarrhoea can also result from a number of non-infectious causes and conditions. [13] Some of these conditions include lactose intolerance, irritable bowel syndrome, ${ }^{[14]}$ non-celiac gluten sensitivity, celiac disease, inflammatory bowel diseases such as ulcerative colitis, hyperthyroidism, bile acid malabsorption, chronic ethanol ingestion and the effect of certain medications such as laxatives, antacids, heartburn medications, antibiotics, anti-neoplastic drugs, antiinflammatories as well as many dietary supplements, $[12,13,15,16]$

The management of diarrhoea requires establishing the underlying cause and instituting specific therapies. This involves the replacement of the lost fluids and electrolyte with rehydration therapy as well as using medications; sometimes the latter may be beneficial and/or contraindicated in certain situations. The management focuses on preventing excessive fluid and electrolyte losses, dietary care, relieving symptoms, treating curable causes and treating secondary disorders. [17] Most of the drugs used in managing diarrhoea cause serious adverse effects such as vomiting, intestinal obstruction, and bronchospasm, which limit their usefulness. Anti-diarrhoeal medications such as Loperamide (Imodium) and Bismuth subsalicylate are widely used in the management of diarrhoea; although they may be beneficial, their use is limited in certain situations and also in a severe disease state. [18] They suffered adverse effects such as abdominal pain, constipation, dry mouth, urinary retention, nausea and vomiting, dizziness, paralytic ileus, tinnitus, black stool, dark tongue, among others. For this reason, there is a need for effective alternative therapy with fewer or no side effects.

Many medicinal plants are used for treating diarrhoea; one such is Newbouldia laevis. Newbouldia laevis (P beauv) seem (whole plant) or boundary tree known as "Aduruku" in Hausa language, "Ogirisi" in Igbo language and "Akoko" in Yoruba language, is a medium-sized angiosperm of the Bignoniaceae family. It is a very popular plant in the African continent and highly valuable due to its numerous immense benefits to the human race. ${ }^{[19]}$

In Nigeria, the plant has been found to be effective in the treatment of elephantiasis, dysentery, arthritis, syphilis, pile and as a vermifuge for roundworms. [20] The stem bark has been used variously for febrifuge, wound dressing, abdominal ache, [21] but has not been investigated for its anti-diarrhoeal activity. The objective of the present study was to assess the 
anti-diarrhoeal activity of ethanolic stem bark extract of Newbouldia laevis in castor oil-induced diarrhoea in rats.

\section{Methods}

Animal collection and housing:

Wistar Albino rats with body weight ranging from $150 \mathrm{~g}$ to $200 \mathrm{~g}$ were purchased from the animal house at the University of Ibadan, Ibadan, Oyo State. All the animals were housed, fed and treated in accordance with the in-house guidelines for animal care. Animals were kept for two weeks in other to acclimatize them prior to the investigation. During this time, they were given standard pellet diet and water ad libitum.

This animal experimentation was carried out according to the guidelines of Institutional Animal Ethics Committees (IAEC).

\section{Collection of plant samples}

The stem bark of Newbouldia laevis was collected from Abeokuta, Ogun State, Nigeria in June 2016. The plant was identified and its botanical identity was confirmed and authenticated at the Herbarium section of the Department of Botany University of Lagos, Akoka, Lagos, Nigeria, with Voucher specimens (LUH 6085), which was preserved and stored at the herbarium for future references.

\section{Extract preparation}

The fresh stem bark of Newbouldia laevis was airdried at room temperature and then oven-dried at a temperature of $40^{\circ} \mathrm{C}$. The dried stem was then reduced to a coarse powder using a grinding machine. It was weighed; $500 \mathrm{~g}$ of the powdered plant was extracted with four litres of $90 \%$ ethanol $\left(\mathrm{BDH}\right.$, England $\left.^{\circledR}\right)$ in a cold maceration process for 72 hours and was then filtered with a clean white handkerchief. After filtration, the ethanol was removed from the extract under pressure using a rotator evaporator in the distillation flask to obtain the crude extract. The extract was further concentrated to dryness in a water bath. This yielded brownish residue $(15.7 \%)$, which was stored in a refrigerator in an airtight container (universal bottle) until it was ready for use.

\section{Extract Reconstitution}

The extract was reconstituted by suspending $3 g$ of crude extract in $10 \mathrm{ml}$ of distilled water to obtain a stock solution of $300 \mathrm{mg} / \mathrm{kg}$.

\section{Castor oil-induced Diarrhoea [22]}

Overnight fasted twenty-five (25) albino rats were randomly divided into five (5) groups of five rats per group $(n=5)$. The rats in Group 1 (negative control group) were given $0.2 \mathrm{ml}$ distilled water orally. The rats in Groups 2, 3 and 4 were treated with the extract at doses of $250 \mathrm{mg} / \mathrm{kg}, 500 \mathrm{mg} / \mathrm{kg}$ and $1000 \mathrm{mg} / \mathrm{kg}$ Body Weight (BW), by oral route respectively. The rats in Group 5 (positive control group) were treated with Loperamide at the dose of $1 \mathrm{mg} / \mathrm{kg}$. The rats were housed in separate cages having paper placed below for the collection of faecal matters. After an hour of dosing, diarrhoea was induced in the rats by oral administration of castor oil $(1.0 \mathrm{ml} / \mathrm{rat})$. The rats were then observed for the frequency and consistency of faecal materials. The number of both hard and soft pellets was counted every hour over the next four hours for each rat.

For this study, diarrhoea was defined as the presence of stool with a fluid material that stained the paper placed beneath the cages. Percent inhibition (PI) was calculated as [22]:

PI $=$ Mean defaecation (control group - treated group)/ Mean defaecation of the control group $(\times 100)$

In vivo effect of the extract on Charcoal meal Transit in Rats [23]

Overnight fasted twenty-five (25) albino rats were randomly divided into five (5) groups of 
five rats per group $(n=5)$. The rats in Group 1 (negative control group) was given $0.2 \mathrm{ml}$ distilled water orally while the rats in Groups 2, 3 and 4 were treated with the extract at doses of 250,500 and $1000 \mathrm{mg} / \mathrm{kg}$ BW by oral route respectively and the rats in Group 5 (positive control group) were treated with Loperamide at the dose of $1 \mathrm{mg} / \mathrm{kg}$. Thirty minutes later, $1 \mathrm{~mL}$ of charcoal meal $(10 \%$ activated charcoal and $10 \% \mathrm{CMC}$ ) were administered to all the groups of rats to study the gastrointestinal charcoal meal transit. After 30 minutes of charcoal meal administration, the rats were sacrificed, the distance traveled by charcoal meal (gastrointestinal charcoal meal transit) was measured and expressed as a percentage of the total length of the small intestine (from the pylorus to the ileo-caecal junction).

\% Intestinal Transit $=$ Length passed by charcoal meal $(\mathrm{cm}) /$ Length of GIT $(\mathrm{cm})$

\section{Statistical analysis}

The results obtained were expressed as the Mean \pm Standard Error of Mean (SEM). Statistical analysis was done using One Way Analysis Of Variance (ANOVA), followed by the Dunnett Multiple Comparison Test. Differences were considered significant when the P-value was less than 0.05 .

\section{Results}

Result for Anti-diarrhoeal effect of the extract in rats Newbouldia laevis stem bark extract significantly $(\mathrm{p}=0.0246)$ reduced the mean number of defaecation as the dose increased. The number of stool at 1st, 2nd, 3rd and 4th hours for the stem bark extract at $250 \mathrm{mg} / \mathrm{kg}, 500 \mathrm{mg} / \mathrm{kg}$, $1000 \mathrm{mg} / \mathrm{kg}$ and Loperamide significantly $(\mathrm{p}=$ 0.0246) decreased, the negative control group had the highest mean number of defaecation, meaning that there was no inhibition of diarrhoea in that group. The percentage inhibition of defaecation of Newbouldia laevis stem bark extract at $1000 \mathrm{mg} / \mathrm{kg}(72.9 \%)$ was found to be higher than the effect produced by the standard anti-diarrhoeal drug Loperamide (56.2\%) (Table I).

Result of the effect of Newbouldia laevis stem back extract on Charcoal- meal-altered induced gastrointestinal motility rats

Newbouldia laevis stem bark extract significantly $(\mathrm{p}=0.0399)$ reduced the gastrointestinal movement of charcoal meal in the treated rats. This implies that the extract inhibited the intestinal transit of the charcoal meal, thereby increasing the time of stay of the charcoal meal in the intestine. However, Newbouldia laevis stem bark extract $(1000 \mathrm{mg} / \mathrm{kg})$ exhibited a much more marked reduction in gastrointestinal motility $(24.0 \%)$ with a charcoal meal at 30 minutes study (Table II).

Table I: Effect of ethanolic stem bark extract of Newbouldia Laevis on castor oil-induced diarrhoeal in rats

\begin{tabular}{llcll}
\hline Treatment & $\begin{array}{l}\text { No of rats with } \\
\text { diarrhoeal }\end{array}$ & \% protection & Mean defecation & \% inhibition of defecation \\
\hline Dist.water (0.2ml/rat) & $5 / 5$ & 0.0 & $2.1 \pm 0.4$ & \\
NL $\mathbf{2 5 0} \mathbf{m g} / \mathbf{k g}$ & $4 / 5$ & 20.0 & $1.64 \pm 0.3^{*}$ & 21.9 \\
NL 500 $\mathbf{m g} / \mathbf{k g}$ & $3 / 5$ & 40.0 & $1.14 \pm 0.1^{*}$ & 45.7 \\
NL 1000 $\mathbf{m g} / \mathbf{k g}$ & $1 / 5$ & 80.0 & $0.57 \pm 0.22^{*}$ & 72.9 \\
Loperamide 1mg/kg & $2 / 5$ & 60.0 & $0.92 \pm 0.16$ & 56.2 \\
\hline
\end{tabular}

NL - Newbouldia laevis. Values are expressed as Mean \pm SEM, ${ }^{*} p<0.05$ significant compared to control. 
Table II: Effect of ethanolic stem bark extract of Newbouldia Laevis on gastrointestinal motility with a charcoal meal in rats

\begin{tabular}{ll}
\hline Treatment & Gastrointestinal motility (Mean \pm SEM) \\
\hline Distilled water $\mathbf{( 0 . 2 m l / r a t )}$ & $50.8 \pm 4.4$ \\
NL (250 $\mathbf{m g} / \mathbf{k g})$ & $33.8 \pm 5.5$ \\
NL (500 $\mathbf{m g} / \mathbf{k g})$ & $31.4 \pm 4.4$ \\
NL (1000 $\mathbf{m g} / \mathbf{k g})$ & $24.0 \pm 2.8$ \\
Loperamide $\mathbf{1 m g / k g}$ & $32.6 \pm 2.6$ \\
\hline
\end{tabular}

NL - Newbouldia laevis. Values are expressed as Mean \pm SEM *P<0.05 significant compared to control

\section{Discussion}

In this study, diarrhoeal disease, which is the second most common cause of morbidity and mortality among people in developing countries, was investigated. The disease is characterized by the passage of watery stool with or without blood. It is more common in infants and children under five years of age, making it a major health problem requiring urgent attention in the area of its treatment and prevention.

A number of medicinal plants were reported to have anti-diarrhoeal property, [24] and have been used traditionally for treating diarrhoea in different countries. Some of them include Amaranthus caudatus, Coffea arabica, Balanites rotundifolia, Boscia coriacea, Cissampelos pareira, and Plumbago zeylanica. [25] The result of the present study showed that the extract of Newbouldia laevis at doses of $250 \mathrm{mg} / \mathrm{kg}$, $500 \mathrm{mg} / \mathrm{kg}$ and $1000 \mathrm{mg} / \mathrm{kg}$ BW showed a significant activity against castor-oil induced diarrhoea in rats. The extract reduced the mean number of defecation of the treated rats when compared with the untreated control (using distilled water). However, the activity of the extract at $1000 \mathrm{mg} / \mathrm{kg}$ was most pronounced than the effect produced by the most widely used anti-diarrhoeal drug, Loperamide.

The study also showed that the extract dosedependently produced a reduction in gastrointestinal movement of the charcoal meal, which implies a reduction in the gastrointestinal motility of the treated rats. The reduction in gastrointestinal motility increases the time of stay of gastrointestinal luminal contents, thus promoting absorption of fluid and electrolytes from the intestine.

A similar anti-diarrhoeal activity was observed in some previous studies on the anti-diarrhoeal activities of some medicinal plants. [26-27] The findings from this study are consistent with the reports of Raymond et al., [28] in which Newbouldia laevis leaf extract produced a significant percentage inhibition of defaecation in castor oil-induced diarrhoea in rats. That study also reported that Newbouldia laevis produced a more significant inhibition of the movement of the charcoal meal when compared with the standard drug used. Therefore, the present study supports the use of medicinal plants as an effective treatment for the diarrhoeal disease. Anti-diarrhoeal properties of most medicinal plants were found to be due to the presence of tannins, alkaloids, saponins, flavonoids, steroids, and terpenoids in them. [29] Reports on phytochemical screening of the plant extract used in this study revealed the presence of high levels of flavonoids, tannins [30] and zinc among others and these are noted for their beneficial effects. These phytochemicals may be responsible for the anti-diarrhoeal activity of the extract of Newbouldia laevis observed in this study. 
It has been previously demonstrated that tannins are known to decrease the irritability of the small intestine thereby reducing its peristaltic index. Flavonoids, on the other hand, were reported to have the ability to inhibit intestinal motility, inhibit contractions induced by spasmogenics and also inhibit prostaglandin $\mathrm{E}_{2}$ biosynthesis. [31] In addition, flavonoids possess antioxidant properties that were known to be responsible for the inhibitory effects of several enzymes including those involved in arachidonic acid metabolism. Reports also showed that zinc, an antioxidant element which gives protection against free radical damage, plays a role in immune functions, protein synthesis, wound healing, cell growth, and differentiation, as well as intestinal transport of water and electrolytes, results in $25 \%$ reduction in the duration of acute diarrhoea and $40 \%$ reduction in treatment failure or death in persistent diarrhoea. [32] Studies have also shown that zinc deficiency results in alterations in immune response which can contribute to increased susceptibility to infections, impaired growth, impaired wound healing and chronic diarrhoea among others. [33] Therefore, the ingestion of zinc-containing medicinal plants can help to reduce the risk, duration, and severity of diarrhoea.

The present study used castor-oil to induce diarrhoea in rats. Castor oil is a triglyceride characterized by a high content of the hydroxylated unsaturated fatty acid ricinoleic acid. [34] After oral ingestion of castor oil, ricinoleic acid is released by intestinal lipases and this induces laxative effect by causing the irritation and inflammation of the intestinal mucosa, leading to the release of prostaglandins. The latter stimulates the net secretion of fluid and electrolytes in the small intestine. Therefore, inhibitors of prostaglandin biosynthesis delay castor oil-induced diarrhoea. [35] It is possible that the anti-motility effect of both tannins and flavonoids, coupled with the ability of flavonoids to inhibit prostaglandin $E_{2}$ biosynthesis and its anti-oxidant properties could be responsible for the anti-diarrhoeal activity of Newbouldia laevis.

Therefore, when considering herbal products as a treatment option for diarrhoea, it is of utmost importance to use flavonoid-containing medicinal plants to achieve a desirable therapeutic effect.

\section{Conclusion}

The present study shows that stem bark extract of Newbouldia laevis possesses a significant antidiarrhoeal property and this supports the traditional use of the plant in the treatment of diarrhoea.

Acknowledgement: The authors are thankful to Mr. Ndimele of the Department of Pharmaceutical Chemistry, Faculty of Pharmacy, Olabisi Onabanjo University, Nigeria for providing support and access to research facilities.

Authors' Contributions: All the authors participated in the design of the study, literature search, data acquisition, and analysis, drafting of the manuscript and approval of the final version of the manuscript.

Conflicts of Interest: None.

Funding: Self-funded.

Publication History: Submitted 11 June 2019; Revised 30 August 2019; Accepted 10 September 2019.

\section{References}

1. William J.S and William E.W. Gastrointestinal Disorders: Diarrhoea, Constipation and Irritable Bowel Syndrome. Pharmacotherapy; Pathophysiologic 
Approach. 6th Edition. McGraw Hill. 2005. pp 677.

2. Rang HP, Dale MM, Ritter JM, Moore PK. Drugs affecting major organ systems: The Gastrointestinal Tract. 5th Edition. Church Hill. 2003. pp 376.

3. World Health Organization. Diarrhoea disease Fact sheet N0330. 2013.

4. Laloo D, Hemalatha S. Ethnomedicinal plants used for Diarrhoea by Tribals of Meghalaye, Northeast India. Pharmacog Rev 2011; 5(10): 147-154.

5. Tripathi KD. Gastrointestinal Drugs: Drugs used in Constipation and Diarrhoea. Essentials of Medical Pharmacology. 6th Edition. Jaypee Brothers Medical Publishers (P) Ltd. 2008. pp 657.

6. World Health Organization. "Diarrhea disease Fact sheet N³30. 2013. Retrieved 9th July 2014.

7. Global Burden of Disease. Study 2013 Collaborators "Global, regional, and national incidence, prevalence, and years lived with disability for 301 acute and chronic diseases and injuries in 188 countries, 1990-2013: a systematic analysis for the Global Burden of Disease Study 2013". Lancet 2015; 386(9995): 743-800. doi: 10.1016/s0140-6736(15)60692-4.

8. CDC. Global Diarrhoea Burden 2013. Retrieved 18 June 2014.

9. Global Burden of Disease. Mortality and Causes of Death Collaborators. "Global, regional, and national age-sex specific allcause and cause-specific mortality for 240 causes of death, 1990-2013: a systematic analysis for the Global Burden of Disease Study 2013". Lancet 2013; 385(9963): 117-171. doi: 10.1016/S0140-6736(14)61682-2.

10. Global Burden of Disease. Diarrhoea Disease Collaborators. Estimates of the global, regional, and national morbidity, mortality, and etiologies of Diarrhoea in 195 countries: a systematic analysis for the Global Burden of Disease Study 2016. Lancet Infect Dis 2016; 18(11): 1211-1228. doi: 10.1016/S14733099(18)30362-1.

11. Nelson R. Diarrhoea remains a leading cause of Global Mortality and Morbidity. Gastroenterology. Infectious Disease Advisor. Haymarket Media Inc. 2018.

12. Sapone A, Bai JC, Ciacci C, Dolinsek J, Green $\mathrm{PH}$, Hadjivassiliou $\mathrm{M}$, et al. Spectrum of gluten-related disorders: Consensus on New Nomenclature and Classification. BMC Med (Rev) 2012; 10: 13. doi: 10.1186/1741-7015-1013.

13. Abdelmalak B, Doyle J. Anesthesia for otolaryngological surgery. Cambridge University Press. 2013. pp. 282-287.

14. DuPont HL. Acute infectious diarrhoea in immunocompetent adults. New Engl J Med 2014; 370(16): 1532-1540.

15. Slattery SA, Niaz O, Aziz Q, Ford AC, Farmer AD. Systematic review with metaanalysis: the prevalence of bile acid malabsorption in the irritable bowel syndrome with diarrhoea. Alimentary Pharmacol Therap 2015; 42(1): 3-11.doi: 10.1111/apt.13227.

16. Moon C, Zhang W, Sundaram N, Yarlagadda S, Reddy VS, Arora K, Helmrath MA, Naren AP. Drug-induced secretory diarrhoea: A role for CFTR. Pharmacol Res 2015: $\quad$ 102: 107-112. doi:10.1016/j.phrs.2015.08.024.

17. William JS, William EW. Gastrointestinal Disorders: Diarrhoea, Constipation, and Irritable Bowel Syndrome. Pharmacotherapy; Pathophysiologic Approach. 6th Edition. McGraw Hill. 2005. pp 679. 
18. DuPont HL. Acute infectious diarrhoea in immunocompetent adults. New Engl J Med 2014; 370(16): 1532-1540. doi: 10.1056/nejmra1301069.

19. Umeokoli BO, Ekeh MN, Eze P, Umeyor C, Abba C. Improved Gastric Lesion of Ulcerogenic Mice treated with Bark Extract and Fractions of Newbouldia laevis. Afr J Pharm Pharmacol 2015 9(21): 553-560.

20. Usman H, Osuji JC. Phytochemical and Invitro Antimicrobial Assay of the Leaf extract of Newbouldia laevis. Afr J Tradit Complem Altern Med 2007; 4(4): 476-480.

21. Iwu MM. Handbook of African Medicinal Plants. CRC Press, Inc. London. 2000. pp 19-

22. Gnanasekar N, Perianayagam JB. Influence of sodium curcuminate on castor-oil induced diarrhoea in rats. Indian J Pharmacol 2004; 36: $177-178$.

23. Shoba F.G, Thomas M. Study of antidiarrhoea activity of Four Medicinal Plants in Castor oil-induced Diarrhoea. J Ethnopharmacol 2001; 76: 73-76.

24. Yakubu M, Toyin OF, Khadijat SS, Ajiboye TO, Bamisaye FA, Quadri AL. Antidiarrhoea activity of aqueous leaf extract of Ceratotheca sesamoides in rats. Bangladesh J Pharmacol2012; 7: 14-20.

25. Abera B. Medicinal plants used in traditional medicine by Oromo people, Ghimbi District, Southwest Ethiopia. J Ethnobiol Ethnomed 2014; 10(1): Article40.

26. Akintola AO, Adedosu OT, Kehinde BD, Ibikunle GJ. Evaluation of Anti-diarrhoea Activity of the ethanolic stem bark extract of Vernonia amygdalina in experimental animals. J Nat Sci Res. 2016; 6(10): 61-66.

27. Akuodor GC, Muazzam I, Usman-Idris M, Megwas UA, Akpan JI, Chilaka KC, et al. Evaluation of the Anti-diarrhoea activity of methanol leaf extract of Bombax buonopozense in rats. Ibnosina J Med BS 2011; 3(1): 15-20.

28. Ibeh RC, Ikechukwu GC, Ijioma SN, Nwankwo CI, Singh AK, Asadi-Samani M, et al. Anti-spasmolytic and anti-diarrhoeal activities of Newbouldia laevis, Cola nitida and Acanthus montanus Extracts on Gastrointestinal Muscles. J Pharmacol Toxicol 2019; 14(1):1-8. doi: 10.3923/jpt.2019.1.8.

29. Havagiray R, Ramesh C, Sadhna K. Study of Anti-diarrhoea activity of Calotropisgignatear b.r in experimental animals. J Pharmacol Pharmaceut Sci 2004; 7: 70-75.

30. Anaduaka EG, Ogugua VN, Egbs S, Apeh VO. Investigation of some important Phytochemicals, Nutritional Properties and Toxicological Potentials of Ethanolic extracts of Newbouldia laevis leaf and stem. Afr J Biotechnol 2013; 12(40): 5846-5854.

31. James N, Bernard M, Haruna M, Larry S, John K. Antidiarrhoeal Activity of Ethanolic fruit extract of Psidium guajava in castor-oil induced Diarrhoea in albino rats. Natl J Physiol Pharm Pharmacol 2013; 3(2): 191197.

32. Bhutta ZA, Bird SM, Black RE. Therapeutic effects of oral zinc in acute and persistent diarrhoea in children in developing countries: Pooled analysis of randomized controlled trials. Am J Clin Nutri 2000; 72(6): 1516-1522.

33. Roohani N, Hurrel R, Kelishadi R, Schulin R. Zinc and its importance for human health: An integrative Review. J Res Med Sci 2013; 18(2): 144-157.

34. Mekeon TA, Lin A, Stafford AE. Biosynthesis of Ricinoleate in Castor oil. Adv Exp Med Biol 1999; 464: 37-47. doi: 10.1007/978-14615-4729-4. 
35. Brijesh S, Daswani P, Terali P, Antia N, Birdi T. Studies on the anti-diarrhoeal activity of Aegie marmedosunripe fruit. Validating its traditional usage. BMC Complement Altern Med 2009; 9(47): 1-12.
@ळ@

This is an Open Access document licensed for distribution under the terms and conditions of the Creative Commons Attribution License (http:/ / creativecommons.org/licenses/by-nc/4.0). This permits unrestricted, non-commercial use, reproduction and distribution in any medium provided the original source is adequately cited and credited. 